\title{
Treatment of multiple sclerosis with interferon $\beta$ : an appraisal of cost-effectiveness and quality of life
}

\author{
David Parkin, Ann Jacoby, Paul McNamee, Paul Miller, Simon Thomas, David Bates
}

\begin{abstract}
Objective-To evaluate the cost-effectiveness of interferon beta-1b (IF $\beta-1 b)$ for relapsing-remitting multiple sclerosis (RRMS).

Methods-Construction of a cost-effectiveness model using published data on IF $\beta-1 b$ effectiveness and the natural history of RRMS, and new data on costs and quality of life (QoL) from a sample of 102 patients with RRMS and resident in northern England.

Results-Poorer QoL was found for patients with multiple sclerosis compared with the general population; those who had had a relapse; those with worse states identified by a clinical measure (expanded disability status scale (EDSS)). Relapses have effects over several months. Health state valuations were higher than in the general population. Costs were higher in relapse than remission and for worse EDSS states. IF $\beta-1 b$ costs were larger than cost savings. The best costeffectiveness estimate was $£ 28700$ per relapse avoided, which is $£ 809900$ per QALY gained; or $£ 328300$ per QALY gained allowing for effects of progression over 5 years. Estimates were robust to changes in assumptions.

Conclusions-The impact of multiple sclerosis on QoL is substantial. Future trials should base outcomes measurement on QoL and be better linked to natural history and cost data. IF $\beta-1 b$ produces important occasional short term QoL gains, but small gains in QALYs overall and large additional costs.

(F Neurol Neurosurg Psychiatry 2000;68:144-149)
\end{abstract}

Trent Institute for

Health Services

Research, The Medical

School, Queens

Medical Centre,

University of

Nottingham,

Nottingham,

NG7 2UH, UK

P Miller

Correspondence to:

Paul McNamee, Department

of Epidemiology and Public

Health, School of Health

Sciences, University of

Newcastle, Newcastle Upon

Tyne, NE2 4HH, UK

email

Paul.McNamee@ncl.ac.uk

Received 26 March 1999 and in final form

10 September 1999

Accepted 17 September 1999 Keywords: costs; quality of life; multiple sclerosis; interferon $\beta$

Until recently, no specific therapy was available for multiple sclerosis. After clinical trials which established that interferon $\beta$ preparations reduce multiple sclerosis disease activity, ${ }^{1-4}$ three products have been licensed in the United Kingdom-interferon $\beta$ 1-b (IF $\beta-1 b)$ and two interferon $\beta$ 1-a (IF $\beta$-1a) compounds. IF $\beta-1 \mathrm{~b}$ is now also licensed for secondary progressive disease. ${ }^{5}$

At present, their role in clinical practice remains uncertain. The trials are not easily extrapolated to general patient populations and provide no information about quality of life effects and cost-effectiveness. The National
Health Service Executive's health technology assessment programme commissioned a 1 year project to assess the cost-effectiveness of IF $\beta-1 b$ (which at the time was the only licensed product) in relapsing-remitting multiple sclerosis (RRMS). ${ }^{6}$ A cost-effectiveness model was constructed using published data on effectiveness and the natural history of multiple sclerosis and new data on costs and quality of life. There is a danger that cost-effectiveness summaries may suppress important detail; we therefore examined the quality of life of people with multiple sclerosis more closely than economic appraisal strictly requires.

\section{Methods}

The cost-effectiveness of IF $\beta-1 \mathrm{~b}$ compared with standard management was measured by cost-effectiveness and cost-utility ratios, defined respectively as cost per relapse avoided and cost per quality adjusted life-year (QALY) gained. This was based on the IF $\beta-1 \mathrm{~b}$ trials' reported clinical outcomes. ${ }^{12}$ However, resource use and quality of life and utilities (the QALY adjustment weights) were not reported, requiring collection of new data and a model to link data from different sources. The new data could not directly compare patients receiving and not receiving IF $\beta-1 b$, but provided a means to generate such comparisons.

\section{DATA COLLECTION}

Two samples of people with RRMS were chosen from the catchment area of the neurology service at Newcastle-Upon-Tyne: 40 patients who had experienced a relapse in the 6 months preceding a fixed date (the "recent relapse group"); and 62 who had not (the "remission group"). Subjects were chosen as they were identified from medical records by a research nurse.

Our study only identified relapses via medi- 
the EuroQoL-5 Dimension instrument, EQ- $5 \mathrm{D}^{7}$ was used in the patient questionnaires (see quality of life section below), giving population based values via the measuring and valuing health $(\mathrm{MVH})$ tariff developed at the University of York, UK. ${ }^{8}$ Secondly, utilities were measured directly for 50 patients, 26 from the recent relapse group and 24 from the remission group.

Linkage between multiple sclerosis natural history data, trial outcomes, and cost and quality of life data was through the expanded disability status scale (EDSS). ${ }^{9}$ As this is not routinely collected, estimates were made for those patients managed by the consultant neurologist (DB).

QUALITY OF LIFE

We reviewed available patient based measures of QoL in multiple sclerosis, opting for the multiple sclerosis quality of life 54 item scale (MSQOL).$^{10}$ This measure comprises a well validated generic health status instrument, the short form (SF) $36^{11}$ and additional multiple sclerosis specific items. It addresses 12 QoL domains: physical and social function, roles physical and emotional, pain, energy, mental and general health, health distress, sexual function, cognitive function, and overall QoL. Composite scores for physical and mental health can be calculated. As for the SF-36, scores on the MSQOL range from 0-100, with higher scores indicating better functioning ( $0=$ worst possible, $100=$ best possible). MSQOL has been shown in a United States sample to have good psychometric properties ${ }^{10}$ (high internal consistency, test-retest reliability and reproducibility; evidence of construct validity). As the time frame set by the funding body did not permit a pilot study to examine the acceptability to patients of four detailed sexual function items which might offend some and so reduce response rates, we omitted them and included only the single item concerning sexual satisfaction.

To support the use of this adapted version of MSQOL, psychometric analysis using the MAP-R multitrait scaling analysis package $^{12}$ was performed. This showed that MSQOL performs similarly for United Kingdom as for United States patients; and its psychometric properties were generally acceptable. Compared with United States patients, there were marked ceiling effects for two scales, role emotional and bodily pain; and marked floor effects for two scales, role physical and role emotional. Floor effects were particularly problematic for the first, suggesting that MSQOL may underestimate marked differences in level of functioning in this domain between different patient subgroups. Full details of the psychometric analysis are reported elsewhere. ${ }^{6}$

We also collected the EQ-5D, ${ }^{7}$ a generic measure with five dimensions-mobility, self care, usual activities, pain/discomfort, and anxiety/depression. The EQ-5D notation represents a composite health state denoting the level of severity in each of the five health domains. For example, 11112 means no problems with walking, self care, usual activities and pain, moderate anxiety/depression; 22222 means moderate problems across all domains. A summary quality of life score (varying between 0 and 1) can then be assigned to each state using the MVH tariff. The tariff was derived from interviews with the United Kingdom general population, which involved asking them to assign values to different health states using the time-trade off method. ${ }^{13}$

The remission group judged quality of life in remission by recording health status over time. They kept a daily quality of life diary for 6 weeks, and at the start and end of this period recorded via a structured questionnaire current MSQOL and EQ-5D status. Because we could not identify patients at the start of a relapse and monitor them, relapses were assessed retrospectively. The recent relapse group recorded in a structured questionnaire how they were currently (MSQOL and EQ-5D) and how they were at the worst of their relapse (EQ-5D). Up to two 3 weekly reminders were sent to non-responders.

\section{UTILITIES}

In face to face interviews subjects valued multiple sclerosis specific health profiles, using the time trade-off method. ${ }^{13}$ These incorporated quality of life effects, described as EQ-5D states, number of relapses, and the probability of disease progression, taken from multiple sclerosis natural history data ${ }^{14-17}$ and the IF $\beta-1 b$ trial. One scenario described multiple sclerosis with no drug therapy, matching the trial outcomes for the placebo group. Another described multiple sclerosis with (unnamed) drug therapy, matching the therapy group's outcomes. A third described more severe multiple sclerosis effects without drug therapy. Subjects also valued five EQ-5D profiles likely to be encountered by patients with RRMS, which could be directly compared with the MVH values.

\section{COsTs}

Service use data for 6 months were abstracted from hospital case notes, including inpatient stays (specialty, number of admissions, and duration of stay), day cases and outpatient visits (specialty and number of visits), drugs (name, dosage, and duration), procedures and tests (type and frequency), and appliances. The patient questionnaires included questions on primary and community services, recording number of visits by professional group.

The Chartered Institute of Public Finance and Accountancy (CIPFA) database ${ }^{18}$ provided inpatient and day case unit costs. Drug costs were from the British National Formulary ${ }^{19}$; IF $\beta-1 \mathrm{~b}$ costs included administration and monitoring. Procedure and test costs were from the Trust providing the patients' specialist service. Costs for appliances and community services were taken from a previous report. ${ }^{20}$

\section{COST-EFFECTIVENESS MODELS}

The IF $\beta-1 b$ trial reported reduced numbers of relapses but no statistically significant effect on disability. This requires a simple model which 
Table 1 Demographic and clinical characteristics of participants in a survey of people with relapsing-remitting multiple sclerosis

\begin{tabular}{|c|c|c|}
\hline & $\begin{array}{l}\text { Whole sample } \\
\text { No (\%) }\end{array}$ & $\begin{array}{l}\text { Utilities interview sample } \\
\text { No }(\%)\end{array}$ \\
\hline \multicolumn{3}{|l|}{ Type of respondent: } \\
\hline Remission & $62(61)$ & $24(48)$ \\
\hline Relapse & $40(39)$ & $26(52)$ \\
\hline \multicolumn{3}{|l|}{ Age and sex: } \\
\hline Median age (range) & $42(25-65)$ & $42(28-65)$ \\
\hline Men & $28(28)$ & $17(34)$ \\
\hline Fomen & $73(72)$ & $33(66)$ \\
\hline \multicolumn{3}{|l|}{ Employment status: } \\
\hline Employed & $42(42)$ & $11(22)$ \\
\hline Unable to work & $50(51)$ & $27(54)$ \\
\hline Other & $7(7)$ & $12(24)$ \\
\hline \multicolumn{3}{|l|}{ Disease duration: } \\
\hline$\leqslant 5$ years & $42(42)$ & $17(33)$ \\
\hline$>5$ years $\leqslant 10$ years & $25(26)$ & $17(33)$ \\
\hline$>10$ years & $31(32)$ & $16(33)$ \\
\hline \multicolumn{3}{|l|}{ EDSS score: } \\
\hline $0-3$ & $33(37)$ & $13(32)$ \\
\hline $4-5$ & $32(36)$ & $18(44)$ \\
\hline $6+$ & $24(27)$ & $10(24)$ \\
\hline
\end{tabular}

Table 2 MSQOL mean scores for patients in remission and recently relapsing in a survey of people with relapsing-remitting multiple sclerosis

\begin{tabular}{llll}
\hline Scale: & $\begin{array}{l}\text { In remission } \\
\text { Mean }(S D)\end{array}$ & $\begin{array}{l}\text { Recent relapse } \\
\text { Mean (SD) }\end{array}$ & $\begin{array}{l}2 \text { Tailed } \\
\text { p valuet }\end{array}$ \\
\hline Physical function (PF) & $42.9(28.5)$ & $20.0(18.6)$ & 0.0001 \\
Role physical (RP) & $39.9(40.3)$ & $13.2(28.9)$ & 0.0004 \\
Role emotional (RE) & $64.3(44.0)$ & $53.5(47.5)$ & 0.29 \\
Bodily pain (BP) & $73.1(23.3)$ & $58.6(27.0)$ & 0.01 \\
Mental Health (MH) & $69.4(19.5)$ & $63.7(22.9)$ & 0.25 \\
Energy/vitality (VT) & $39.9(18.9)$ & $32.0(17.7)$ & 0.05 \\
Health distress (HD) & $59.2(26.4)$ & $48.8(30.5)$ & 0.09 \\
Social function (SF) & $66.2(22.7)$ & $47.5(25.9)$ & 0.0006 \\
Cognitive function (CF) & $70.1(25.3)$ & $60.8(29.7)$ & 0.14 \\
Sexual function (SX) & $59.6(32.3)$ & $46.1(33.7)$ & 0.05 \\
General health (GH) & $43.2(21.9)$ & $39.0(22.3)$ & 0.31 \\
Overall quality of life (QOL) & $69.5(61.6)$ & $49.9(20.6)$ & 0.008 \\
Change in health (TRANS) & $47.9(22.2)$ & $31.9(22.6)$ & 0.0007 \\
Physical health composite score & $43.9(16.9)$ & $32.8(15.5)$ & 0.0009 \\
Mental health composite score & $63.5(23.7)$ & $55.6(24.6)$ & 0.11 \\
\hline
\end{tabular}

ॠFor each scale, a few patients did not complete sufficient items to permit computation. Bases on which scale scores were calculated range from 53 to 60 for remission patients; from 38 to 40 for relapse patients.

†Mann-Whitney Test

sums over time resultant cost savings and QALY gains to compare with treatment costs.

However, because other trials may find an impact on progression, a more complex model is required which incorporates this and the natural history of multiple sclerosis. It comprises a hypothetical cohort, within which each patient is at any time at a particular EDSS

Table 3 MSQOL mean scores by expanded disability status scale (EDSS) scores in a survey of people with relapsing-remitting multiple sclerosis

\begin{tabular}{|c|c|c|c|c|}
\hline \multirow[b]{2}{*}{ Scale } & \multicolumn{3}{|l|}{ EDSS score } & \multirow[b]{2}{*}{$p$ Valuet } \\
\hline & $\begin{array}{l}0-3^{\star} \\
\text { Mean (SD) }\end{array}$ & $\begin{array}{l}3.5-5.5^{\star} \\
\text { Mean (SD) }\end{array}$ & $\begin{array}{l}6+^{\star} \\
\text { Mean (SD) }\end{array}$ & \\
\hline Physical function (PF) & $54.2(29.8)$ & $25.9(20.9)$ & $12.6(12.0)$ & $<0.0001$ \\
\hline Role physical (RP) & $44.8(43.0)$ & $19.2(29.1)$ & $15.8(37.5)$ & 0.01 \\
\hline Role emotional (RE) & $67.8(44.0)$ & $55.9(46.7)$ & $45.6(48.7)$ & 0.30 \\
\hline Bodily pain (BP) & $67.7(23.8)$ & $65.2(26.1)$ & $65.2(28.3)$ & 0.92 \\
\hline Mental health $(\mathrm{MH})$ & $71.6(17.5)$ & $67.1(19.5)$ & $59.8(26.8)$ & 0.27 \\
\hline Energy/vitality (VT) & $39.3(17.5)$ & $36.6(19.7)$ & $35.3(21.1)$ & 0.84 \\
\hline Health distress (HD) & $64.3(24.7)$ & $56.3(29.9)$ & $39.3(28.6)$ & 0.01 \\
\hline Social function (SF) & $65.7(26.2)$ & $56.9(23.1)$ & $41.7(23.3)$ & 0.005 \\
\hline Cognitive function (CF) & $71.3(25.9)$ & $67.9(23.7)$ & $54.3(32.5)$ & 0.14 \\
\hline Sexual function (SX) & $69.8(31.6)$ & $48.3(27.5)$ & $42.9(37.2)$ & 0.007 \\
\hline General health $(\mathrm{GH})$ & $42.1(21.8)$ & $37.9(21.5)$ & $38.6(25.3)$ & 0.75 \\
\hline Overall quality of life (QOL) & $79.3(85.1)$ & $53.6(19.1)$ & $49.9(22.9)$ & 0.04 \\
\hline Change in health (TRANS) & $48.3(27.0)$ & $39.8(20.9)$ & $34.5(24.3)$ & 0.25 \\
\hline Physical health composite score & $45.4(18.2)$ & $36.1(15.7)$ & $31.2(15.9)$ & 0.03 \\
\hline Mental health composite score & $67.5(24.2)$ & $59.3(22.9)$ & $49.9(24.5)$ & 0.05 \\
\hline
\end{tabular}

${ }^{\star}$ For each scale, a few patients did not complete sufficient items to permit computation. Bases on which scale scores were calculated range from 26 to 30 for patients with EDSS of 0-3; from 29 to 32 for patients with EDSS of 3.5-5.5; from 19 to 21 for patients with EDSS of 6 and over. †Kruskal-Wallis 1 way ANOVA. level, initially EDSS 3, the average trial baseline. Progression probabilities, taken from the natural history literature, determine the levels in subsequent years; a reduced risk rate, taken from trial estimates, applies to those having therapy. Each patient's illness career is summarised as a "transition state" - for example, EDSS $3 \rightarrow 3$ (no progression), EDSS $3 \rightarrow 5$ (initially EDSS 3, finally EDSS 5), which has a particular level of costs and utility, calculated as an average for each EDSS level weighted by the time spent in it. Full details of the model are reported elsewhere. ${ }^{6}$

Relapse costs and utility losses were the difference in average cost and EQ-5D scores between remission and relapse groups. The remission group provided EDSS level costs. A utility score was calculated for each EDSS level by assigning each patient's EQ-5D state in remission a score from the $\mathrm{MVH}$ tariff and averaging for those at that level.

STATISTICAL ANALYSIS

Analysis of health state differences between remission and relapse patients are reported as two tailed $\mathrm{p}$ values using Mann-Whitney tests. Analysis of EDSS scores are reported using Kruskal-Wallis one way analysis of variance (ANOVA). All statistical tests were performed using SPSS software.

\section{Results}

Table 1 summarises demographic and clinical characteristics. Most patients were women and the average age was 42 years. Half could not work because of long term illness or disability (55\% of the recent relapse group, $47 \%$ of the remission group). Eighty nine were assigned EDSS scores; $37 \%$ scored $0-3,36 \%$ scored $4-5,27 \%$ scored 6 or more; the remaining 13 patients' notes could not be obtained in the time in which data were collected. Except for employment status, the utilities subsample had similar sociodemographic and clinical characteristics compared with the whole sample.

QUALITY OF LIFE

Table 2 shows MSQOL scores for remission and relapse groups. Scores were significantly different $(p<0.001)$ for physical function, role physical, and social function scales, the change in health item, and the physical health composite. As we do not reproduce MSQOL here, it may aid interpretation to know that for physical function, lower scores represent reduced ability to perform a range of gentle through to vigorous physical activities; for role physical, lower scores indicate problems in carrying out work and other regular daily activities; and for social function, lower scores indicate problems in carrying out normal social activities with family and friends. Scores for emotional problems, mental health, cognitive function, and general health perceptions showed least differences. Table 3 reports MSQOL scores for EDSS subgroups. There was a highly significant trend in physical function scores, from 54.2 with an EDSS score $\leqslant 3$ to 12.6 with a score $\geqslant 6(p<0.0001)$. There were also significant differences for social and 
Table 4 Utility values of disease specific scenarios and EQ-5D states from participants in a survey of people with relapsing-remitting multiple sclerosis

\begin{tabular}{llll}
\hline & Mean & (SD) & Mean MVH \\
\hline \multicolumn{2}{l}{ Disease specific scenarios: } & & \\
$\quad$ IF $\beta-1 b$ & 0.870 & $(0.200)$ & NA \\
$\quad \begin{array}{l}\text { Placebo } \\
\text { Severe }\end{array}$ & 0.856 & $(0.195)$ & NA \\
EQ-5D states: & 0.359 & $(0.341)$ & NA \\
11112 & & & \\
11122 & 0.881 & $(0.169)$ & 0.829 \\
21222 & 0.861 & $(0.178)$ & 0.722 \\
21312 & 0.799 & $(0.206)$ & 0.553 \\
22222 & 0.697 & $(0.282)$ & 0.536 \\
& 0.684 & $(0.285)$ & 0.500 \\
\hline
\end{tabular}

$\mathrm{NA}=$ Not applicable

sexual function $(p<0.01)$ and role physical and health distress $(p=0.01)$. There were small but significant differences for both composite scores.

Subjects had markedly lower SF-36 scores than a "normative" United Kingdom general population. ${ }^{21}$ For example, they scored 45 points lower on the physical function scale and 43 lower on the role physical scale than the general population with long standing illnesses; and 59 and 62 respectively lower than those without. Differences were smaller but none the less considerable for social function, energy, and general health.

Ninety six respondents completed all five EQ-5D statements. Only 5\% were currently in state 11111 , compared with $57 \%$ of a general population. ${ }^{22}$ Only 27 out of a possible 243 states were found; 31 patients reported problems with mobility and 32 problems with performing usual activities. The recent relapse group had worse mobility, self care, and pain than the remission group but similar anxiety and depression levels. The recent relapse

Table 5 Cost, quality adjusted life-year, and cost effectiveness estimates from different models

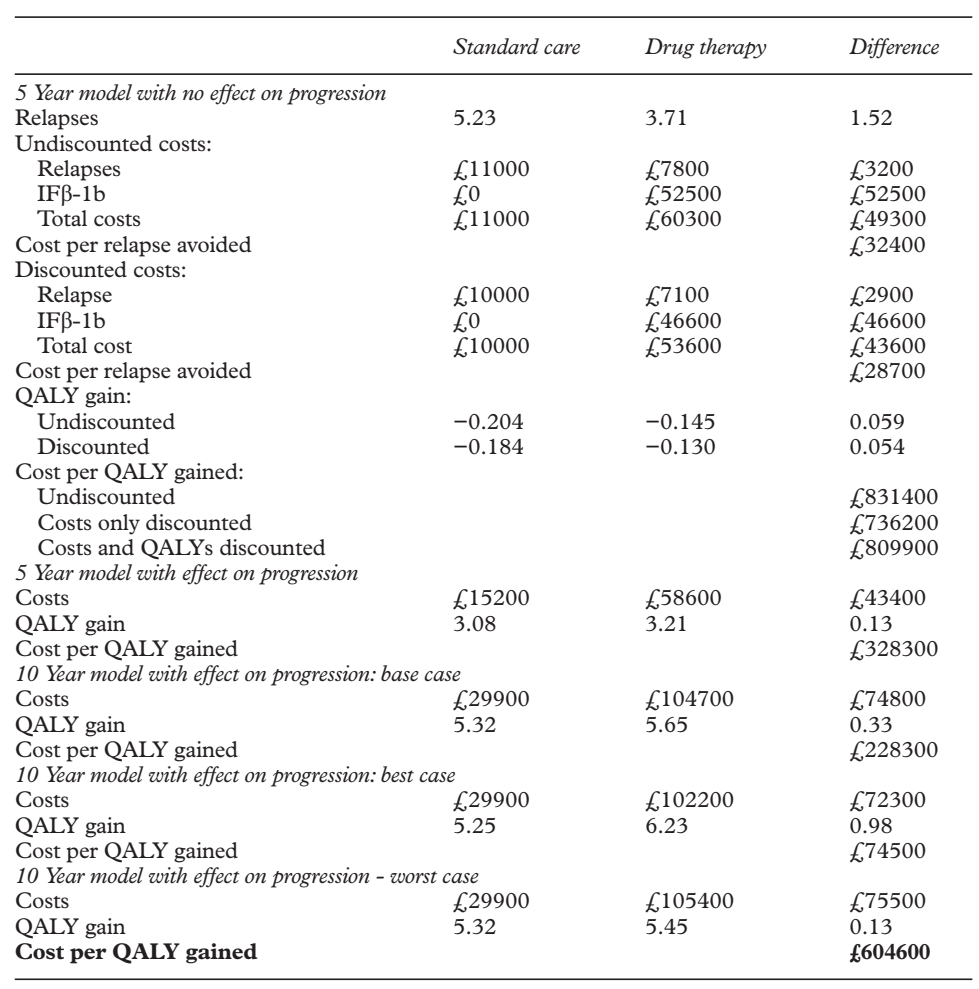

group's profile was significantly poorer in all domains during relapse than currently.

HEALTH STATE UTILITIES AND PREFERENCES Table 4 shows mean utility scores. The IF $\beta-1 b$ and placebo scenario scores were very similar, but the severe scenario scored much lower. Compared with the MVH study, the EQ-5D scores were consistently higher, with greater differences among more severe states.

The results enabled conversion of EDSS scores into utilities. The MVH values were applied to each patient's EQ-5D state, from which the mean value for each studied EDSS level was calculated: 0.71 for EDSS 3, 0.66 for EDSS 4, 0.52 for EDSS 5, 0.49 for EDSS 6, and 0.35 for EDSS 7. Similarly, the utility loss from relapse was calculated by averaging over subjects the MVH values for each EQ-5D state in remission and relapse, and taking the difference: average remission value $=0.604$; average relapse value $=0.136$; a net loss of 0.468 per relapse.

Costs

Average costs were $£ 529$ in the remission group and $£ 2644$ in the recent relapse group, giving relapse costs of $£ 2115$ per patient. The difference was mainly related to use of inpatient and day case and, to a lesser extent, community services, with no difference in outpatient visits, drugs, tests, and appliances. Higher resource use was associated with higher EDSS scores.

COST-EFFECTIVENESS AND COST-UTILITY

ANALYSIS

Table 5 summarises results obtained from the models, showing costs, benefits, and costeffectiveness and cost-utility ratios (rounded to the nearest $f_{100}$ ). The results including only the effect of relapses are presented with and without discounting at the United Kingdom Government recommended rate of $6 \%$, although discounting makes little difference. IF $\beta-1 \mathrm{~b}$ reduced relapses by 1.52 per patient over 5 years, but had discounted net costs of $£ 43600$, giving a cost-effectiveness ratio of $£ 28700$ per relapse avoided. There was a gain of 0.054 discounted QALYs, giving a costutility ratio of $£ 809900$ per QALY gained.

The more complex models, incorporating progression changes, are presented only in discounted form. For a five year model, 0.13 QALYs were gained at a cost of $£ 43400$, giving $£ 328300$ per QALY gained. The robustness of this was tested using one way sensitivity analyses. The figure shows that varying the assumptions for a range of variables produced no important changes in the cost-utility ratio. The largest change was related to the frequency of relapses.

A 10 year model, which uses more assumptions and has greater uncertainty, produced similar results using base case assumptions, and was examined further by altering the assumptions to favourable ("best case") assumptions about progression and IF $\beta-1 \mathrm{~b}$ effectiveness and unfavourable ("worst case") assumptions, equivalent to "no impact on pro- 


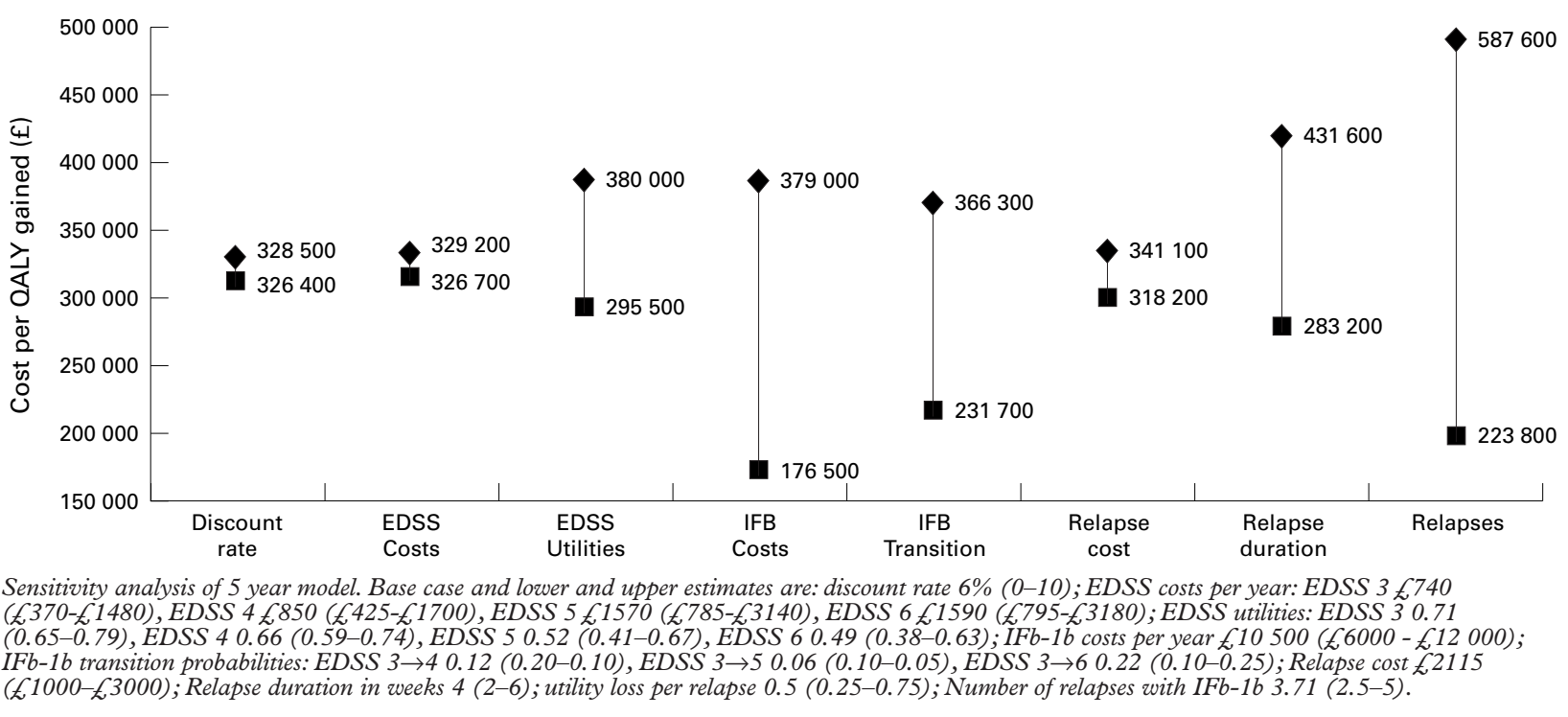

gression". The best case gave $£ 74500$ per QALY gained compared with base case and worst case values of $£ 228300$ and $£ 604600$ respectively (table 5).

\section{Discussion and conclusions}

IF $\beta-1 \mathrm{~b}$ produces important occasional short term quality of life gains, but because they are infrequent they translate into small QALY gains. Even optimistic estimates of longer term gains from delayed progression produce small aggregate QALY gains because few benefit. With large net costs, IF $\beta-1 b$ has a high cost per QALY gained.

It is difficult to compare these results with other studies as, to our knowledge, no previous economic evaluation of interferon $\beta$ therapy has been undertaken using similar methods. A Canadian study calculated comparable cost per relapse avoided ratios of between Can $\$ 48000$ Can $\$ 67000 .^{23}$ However, no attempt was made to translate these effects into QALYs.

This study required many assumptions to construct an economic evaluation from clinical trials designed for a different purpose. Key instruments for data collection were developed rapidly, some data were collected retrospectively, and data collection was not planned to usual statistical specifications. However, the assumptions are evidence based, plausible, and robust to testing. The data instruments performed well and the results seem conclusive within a large margin of uncertainty.

Extensive sensitivity analysis was conducted to ensure that the results could be generalisable to a wide patient population. This was particularly important as our study sample exhibited some clinical differences from the drug trial population with respect to EDSS levels and the measurement of relapses. In addition, we made no attempt to value indirect costs, such as time lost from work and other activities for patients and carers. Although these are likely to have important implications for the level of costs associated with EDSS scores and relapses, we have shown that different values make little difference to the cost/QALY gain ratio (figure and table 5).
Summary effectiveness measures such as relapse rates or EDSS progression may mask important quantifiable effects of multiple sclerosis on quality of life. Measures of QoL are consistent with EDSS scores, which is important as they are widely used by clinicians, but provide important additional information. The outcome measure of choice in evaluations of therapies for multiple sclerosis should therefore be changes in QoL. Such studies must also link outcomes with direct and indirect costs, which has implications for trial design.

These results should help those making prescribing and policy decisions at different levels. Patients and clinicians might consider the extent of the quality of life gains produced by IF $\beta-1 b$ compared with alternatives for improving health. Third party payers have also to consider potential health gains for people with other conditions which could result from alternative uses of IF $\beta-1 \mathrm{~b}$ expenditure, bearing in mind both efficiency, as indicated by the costutility figures, and also equity.

This project was funded by the NHS Health Technology Assessment programme, project number 95/01/2. The views and opinions expressed do not necessarily reflect those of the Department of Health. The following were members of the team that carried out the study at the University of Newcastle Upon Tyne: Ms Julie Doughty, junior research associate, Centre for Health Services Research; Sister Joanna Forsyth, staff nurse, Department of Clinical Neurology; Mrs Sylvia Hudson, project secretary, Centre for Health Services Research. We are grateful to the people who gave their time to take part in our surveys, to Paul Dolan and Karen Gerard for help with the valuation exercise, to Pippa Anderson for access to psychometric analysis software, and to referees of our report to the HTA for their helpful comments.

1 The IFNB Multiple Sclerosis Study Group. Interferon $\beta-1 b$ is effective in relapsing-remitting multiple sclerosis: I clinical results of a multicenter, randomized, double-blind, placebo-controlled trial. Neurology 1993;43:655-61.

2 The IFNB Multiple Sclerosis Study Group and University of British Columbia MS/MRI Analysis Group. Interferon $\beta-1 \mathrm{~b}$ in the treatment of multiple sclerosis: final outcome of the randomised controlled trial. Neurology 1995;45:127785 .

3 Jacobs LD, Cookfair DL, Rudick RA, et al. Intramuscular interferon $\beta$-1 a for disease progression in relapsing multiple sclerosis. Ann Neurol 1996:39:285-93.

4 PRISMS Study Group. Randomised double-blind placebocontrolled study of interferon $\beta-1 \mathrm{a}$ in relapsing/remitting MS. Lancet 1998;352:1498-504.

5 European Study Group on Interferon $\beta-1 \mathrm{~b}$ in Secondary European Study Group on Interferon $\beta-1 \mathrm{~b}$ in Secondary
Progressive MS. Placebo-controlled multicentre randomised trial of interferon $\beta-1 \mathrm{~b}$ in treatment of secondary progressive MS. Lancet 1998;352:1491-7. 
6 Parkin D, McNamee P, Jacoby A, et al. A cost-utility analysis of interferon $\beta$ for multiple sclerosis. Health Technology

7 Williams A. The role of the EUROQOL instrument in $Q A L Y$ calculations. York: University of York, Centre for Health Economics, 1995. (Discussion Paper 130.)

8 Dolan P, Gudex C, Kind P, et al. A social tariff for EuroQoL: results from a UK general population survey. York: University of York: Centre for Health Economics, 1995.

9 Kurtzke JF. Rating neurological impairment in multiple sclerosis: an expanded disability status scale (EDSS). Neurology 1983;33:1444-52

10 Vickrey BG, Hays RD, Harooni R, et al. A health-related quality of life measure for multiple sclerosis. Oual Life Res 1995;4:187-206.

11 Ware JE, Sherbourne CD. A 36-item short-form health survey (SF-36) I. Conceptual framework and item selection. Med Care 1992;30:473-83.

12 Ware JE, Harris WJ, Gandell B, et al. MAP-R for windows: multitrait/multi-item analysis program-revised. Lincoln, multitrait/multi-item analysis

13 Drummond MF, O'Brien B, Stoddart GL, et al. Methods for the economic evaluation of health care programmes. Oxford: Oxford University Press, 1997.

14 Weinshenker BG, Bass B, Rice GPA, et al. The natural history of multiple sclerosis: a geographically based study. i. Clinical course and disability. Brain 1989;112:133-46.

15 Weinshenker BG, Bass B, Rice GPA, et al. The natural history of multiple sclerosis: a geographically based study. ii.
Predictive value of the early clinical course. Brain 1989;112:1419-28.

16 Weinshenker BG, Rice GPA, Noseworthy JH, et al. The natural history of multiple sclerosis: a geographically based study. iii. Multivariate analysis of predictive factors and models of outcome. Brain 1991;114:1045-56.

17 Weinshenker BG, Rice GPA, Noseworthy JH, et al. The natural history of multiple sclerosis: a geographically based study. iv. Applications to planning and interpretations of clinical therapeutic trials. Brain 1991;114:1057-67.

18 Chartered Institute of Public Finance and Accountancy. Health service financial database. London: Health Service Management Association, 1996.

19 British Medical Association, Royal Pharmacological Society of Great Britain. British national formulary. London: BMA, RPSGB, 1996.

20 Netten A, Dennett J. Unit costs of health and social care. Canterbury: University of Kent at Canterbury: Personal Social Services Research Unit, 1996.

21 Jenkinson C, Coulter A, Wright L. Short-form 36 (SF-36) health survey questionnaire: normative data for adults of working age. BMF 1993;306:1437-40.

22 Williams A. The measurement and valuation of health: a chronicle. York: University of York: Centre for Health Economics, 1995.

23 Canadian Coordinating Office for Health Technology Assessment. Interferon $\beta-1 b$ and multiple sclerosis. Ottawa: CCOHTA Technology Overview, 1996.

\section{HISTORICAL NOTE}

\section{Gowers' sign}

Sir William Richard Gowers (1845-1915) is a name hallowed in the minds of most neurologists as one of the great Victorian founders of our discipline. $\mathrm{He}$ is probably best remembered for the remarkable manual first published in 1886, still a continual source of reference and wisdom, remarkable for its wealth of clinical detail, experience, and understanding. Even more remarkable is it when we realise that there was virtually no neurochemistry, minimal electrophysiology, and of course only the most fundamental radiology and neuropathology available to him.

His name is preserved in several eponymous conditions, though paradoxically he inveighed about of the use of eponyms:

"Scientific nomenclature should be itself scientific, not founded upon accidents.

However anxious we may be to honour individuals, we have no right to do so at the expense of the convenience of all future generations of learners."

Gowers' phenomenon, Gowers' distal myopathy, Gowers' solution in the treatment of migraine, Gowers' anterior spinocerebellar tract, are the best known eponyms. There are three Gowers' signs: Pain along the compressed sciatic nerve on passive dorsiflexion of the foot; the irregular contraction of the pupil in early tabes (cf Argyll Robertson); and the climbing up the legs signs in Duchenne dystrophy.
It is the last which I highlight here, as a masterly example of clinical description. ${ }^{1}$ A detailed account of the progressive course and family history, pattern of weakness of muscles, the pseudohypertrophy and his experience of the pathology precede it. He gives full credit to the earlier work of Meryon ${ }^{23}$ and Duchenne.

\section{PSEUDO-HYPERTROPHIC MUSCULAR}

\section{PARALYSIS}

"The difficulty in going upstairs is especially due to the weakness of the extensors of the knee and hip. The defect of the extensors of the hip causes the gait to have a peculiar oscillating characters.

The greatest defect, however, is in the power of rising from the floor, and the most characteristic peculiarity is the mode in which this is achieved, if it be still possible, and no objects near, by which the patient can aid himself. He commonly has not sufficient power to extend the knees when the weight of the trunk is on the upper extremity of the femur, which is then a lever in which power, applied between the fulcrum and the weight, acts at least advantage. He therefore places his hands on his knees, his arms thus bring much of the weight of the upper part of the trunk on the femur close to the fulcrum, between this and the power, which can then act at greater advantage. When the knees are extended, the power of the extensors of the hip may be sufficient to raise the body into the upright position, or the patient may aid them by an upward push with the hand as he takes it off. If, however, these extensors are weak, the hands are often moved higher and higher up the thighs, grasping alternately, and thus pushing up the trunk. To get thus the requisite support, the knees must not he quite extended, and if their extensors have no power, the device cannot be employed, and the patient is altogether unable to rise. In many cases, especially when extension of the hip is easy, the patient achieves the extension of the knees in another way; he puts the hands on the ground, stretches out the legs behind him far apart, and then, the chief weight of the trunk resting on the hands, by keeping the toes on the ground and pushing the body backwards, he manages to get the knees extended, until the trunk is supported by the hands and feet, all placed as widely apart as possible. Next the hands are moved alternately along the ground backwards, so as to bring a larger portion of the weight of the trunk over the legs. Then one hand is placed upon the knee, and a push with this, and with the other hand on the ground, is sufficient to enable the extensors of the hip to bring the trunk into the upright position."

This exemplary description is illustrated by several excellent drawings, from his own hand, which show the same mastery of simple precision and clear exposition that characterise all his writings.

J M S PEARCE 304 Beverley Road, Anlaby, Hull HU10 7BG, York, UK

1 Gowers WR. A manual of disease of the nervous system. London: Churchill, 1886;1:391-4.

2 Meryon E. On fatty degeneration of the voluntary muscles. Lancet 1851 ;ii:588-9.

3 Meryon E. On granular and fatty degeneration of the voluntary muscles. Medico-Chirurgical Transactions 1852;35:73-84.

4 Duchenne GBA Recherches sur la paralysie musculaire pseudo-hypertrophique, ou paralysie myo-sclérosique. Archives Génerales de Médicine 1868;6:5-25; 179-209,305-21; 421-43; $552-88$. 